\title{
Preliminary Investigation of LED Lighting as Growth Light for Seedlings from Different Tree Species in Growth Chambers
}

\author{
Stefania ASTOLFI*, Chiara MARIANELLO, Stefano GREGO, Rosanna BELLAROSA
}

Università della Tuscia, DAFNE, via S.C. de Lellis s.n.c., 01100 Viterbo, Italy; sastolfi@unitus.it (*corresponding author)

\begin{abstract}
The influence of light quality on growth and metabolic activity during pre-cultivation (in miniplug containers) of beech (Fagus sylvatica L.), holm oak (Quercus ilex L.) and wild cherry (Prunus avium) plants was investigated. Seedlings were grown in a growth chamber for a month under light-emitting diode (LED) light or fluorescent light. The LED lamps (Valoya) used in this study emitted a continuous spectrum thanks to a mixture of blue, green, red and far-red LEDs. Our results showed that plant response to light quality seems to be related to the plant species. In particular, in beech seedlings fresh and dry weight, shoot height and leaf area were greatest when plants were cultured under LED light, and lowest under fluorescent lamps. Furthermore, we found that LED-induced reduction of chlorophyll contents in beech and holm oak leaves resulted in an increase of the carboxylase capacity of Rubisco in the same plant species suggesting an improvement of light-use-efficiency in these plants. These results indicate that LED light may be suitable for the culture of plants in tightly controlled environments. The comparison of malondialdehyde levels between LED and fluorescent grown plants strongly supports this idea.
\end{abstract}

Keywords: beech, glutamine synthetase, holm oak, light, lipid peroxidation, Rubisco, wild cherry

\section{Introduction}

A number of environmental concerns currently confront vegetation (Wang et al., 2005). These include soil salinization, drought and decrease in water quality, wind erosion, and losses of biodiversity.

It is well known that vegetation restoration strategies are needed to recovery degraded areas as well as in postfire restoration (Chazdon, 2008; Ciccarese et al., 2012). Among these strategies, abandoned farmland reforestation programs represent one of the most significant means in improving vegetation and controlling soil erosion (Wang et al., 2004). Reforestation requires artificially regenerated forest planting stock material, since in adverse environments, planting seedlings of woody species increases the possibility of recovering ecosystem integrity in comparison to spontaneous successional colonisation or direct sowing (Cole et al., 2011; Wang et al., 2007).

The increasing need to produce high-quality stock of seedlings, which can successfully survive and grow after outplanting (Wilson and Jacobs, 2006), contributes in stressing the importance of nursery culture treatments, namely growing media and fertilization practices, to improve the success of reforestation programs (Grossnickle, 2005; Navarro et al., 2006).

Plants require nutrients, water, $\mathrm{CO}_{2}$, light and temperature at optimal level in order to grow and develop. It has been argued in several reports that changes in environmental conditions, mainly limited by light and water availability, directly affect plant growth and field performance
(Niinemets, 2010; Yamori et al., 2010). The best studied case is most probably the influence of light which drives the processes of photosynthesis by supplying ATP and NADPH needed for $\mathrm{CO}_{2}$ assimilation.

Many studies have clearly shown that modulation in light quality, quantity, and photoperiod can affect plant growth and development (Chen et al., 2004; Zuchi and Astolf, 2012). On the other hand, it is well known that plants respond to irradiance changes through morphological, biochemical and physiological responses. Such responses lead to an adjustment of the growth rate according to the change in availability of energy in the environment (Ariz et al., 2010; Smith et al., 1999).

The illumination of plant growth chambers is typically based on conventional light sources such as fluorescent light (especially cool-white) often used in combination with additional high pressure sodium and/or incandescent lights, providing a broader light spectrum reproducing outdoors conditions (Bubenheim et al., 1988). However these light sources have some limitations due to their short lifetime, high electrical consumption and heat emission.

Recently the utilization of light emitting diodes (LEDs) for plant growth in controlled environment has emerged as an attractive low-cost alternative technology (Yeh and Chung, 2009). LEDs are particularly suitable for plant growth chambers, because of their light weight, small volume and long life (about 100,000 hours) (Tennessen et al., 1994; Yeh and Chung, 2009). Furthermore, LED lighting results in significant energy saving due to emission of very narrow bands of light intensity. 
32

Despite these attractive features of the LEDs system, and the acquired knowledge about the effect of light quality on plant morphogenesis, chlorophyll synthesis and photosynthesis (Massa et al., 2008; Schuerger and Brown, 1994; Tennessen et al., 1994), studies on growth and development of forest trees under different LEDs systems are very limited (Nhut et al., 2002), whereas are more advanced on horticultural plant species (Li et al., 2012; Liu et al., 2011; Stutte et al., 2009).

Therefore, our aim was to examine the effects of LED lighting (Valoya AP67 spectrum, www.valoya.com) on the growth and development of seedlings of three Mediterranean forest species widely used for wood production and environmental and social benefits, namely beech (Fagus sylvatica L.), holm oak (Quercus ilex L.) and wild cherry (Prunus avium L.). The seedlings (miniplugs) were produced using a new forest nursery cultivation method based on pre-cultivation in growth chambers and in very small containers for a very short period of culturing (Mattsson et al., 2010).

In particular, considering that the early growth period (about 30-40 days) is strongly critical for the functional characteristics of seedlings and their field performance, we tested the application of traditional fluorescent lighting or LED lighting in relation to growth (fresh and dry weight, shoot height and leaf area), chlorophyll and $\beta$-carotene contents as well as to protein content in different tree species. Furthermore, we investigated changes in extractable activities of key enzymes involved in C (Rubisco) and N (glutamine synthetase) assimilation pathways in the attempt to relate $\mathrm{CO}_{2}$ assimilation to $\mathrm{N}$ processing when plants are exposed to different light quality. Finally, we studied the changes in lipid peroxidation level in leaves, measured as the content of MDA (malondialdehyde), a widely used stress index of plant membranes.

\section{Materials and methods}

\section{Growing conditions and sampling}

Seeds of three different woody species, beech (Fagus sylvatica L.), holm oak (Quercus ilex L.) and wild cherry (Prunus avium L.), were used in this study.

The recalcitrant holm oak seeds were germinated in sterile sand in a climate controlled chamber and each pregerminated seed with long root tips $( \pm 2 / 3 \mathrm{~mm})$, with the cotyledons cut in half, was transferred into each cavity of the multi-celled containers (mini-plug containers). For breaking the dormancy, the orthodox and dormant seeds of beech and cherry were pretreated respectively for 4 months at $4^{\circ} \mathrm{C}$ and for 8 months at temperatures alternating of $20^{\circ} \mathrm{C}$ for 3 weeks and at $4^{\circ} \mathrm{C}$ for 2 weeks in humid sterile perlite. The seeds remained at $4^{\circ} \mathrm{C}$ until the beginning of germination.

The miniplug plastic container trays (QPD 160/5.5R QuickPot by HerkuPlast-Kubern, Germany) were of identical dimensions $(310 \times 530 \mathrm{~mm}$, density: 975 mini-plugs/ $\mathrm{m}^{2} ; 55 \mathrm{~mm} / \mathrm{h} ; 22 \mathrm{cc}$ ) and were filled with a peat (Preforma PP01, Jiffy $y^{\circ}$ Products, Norway) including a binding agent to stabilize the plug in order to facilitate the transplanting operation. In total, 160 seedlings per species and miniplug container trays were used. After the placing of the pre-germinated seeds, miniplug trays were transferred, for a cultivation period of 30 days, to environmentally controlled growth chambers under white fluorescent lamps Philips-TLD (36W/54 daylight) or Valoya AP67 LED lights. The latter are based on Valoya new technology that creates a wide continuous spectrum thanks to a mixture of blue (photosynthetic photon flux PPF $400-500 \mathrm{~nm}$, $11.5 \%)$, green $(500-600 \mathrm{~nm}, 16.4 \%)$, red $(600-700 \mathrm{~nm}$, 54.7\%) and far red (700-800 nm, 17.4\%) LEDs unlike of the current commercial LED lamps that are based on common discrete red-blue diode combinations generating a narrow red and a narrow blue spectrum skipping several important light energy and light information areas of the spectrum. Environmental conditions in the chambers were set at a $14 \mathrm{~h}$ photoperiod, a photosynthetic photon flux density (PPFD) of $150 \mu \mathrm{mol} \mathrm{m}{ }^{-2} \mathrm{~s}^{-1}$, air relative humidity $(\mathrm{RH})$ of $70 \%$, and a $22^{\circ} \mathrm{C} / 18^{\circ} \mathrm{C}$ day/night temperature. Irradiance was measured routinely at the top of the plants with a quantum sensor. As the plant canopy grew closer to the light banks, $P P F$ levels were maintained by adjusting the height of the trays. Watering was effected every second day, followed by full rotation of the trays in order to ensure uniform growth conditions. Shoots were sampled on day 30 after sowing.

\section{Enzyme extraction and assays}

Enzyme extraction was carried out as described previously by Zuchi et al. (2012). Briefly, frozen tissue (approximately $1 \mathrm{~g} \mathrm{FW}$ ) was ground to a fine powder in a pre-chilled mortar under liquid nitrogen. Cold extraction buffer, containing $50 \mathrm{mM}$ HEPES-KOH (pH 7.4), $5 \mathrm{mM}$ $\mathrm{MgCl}_{2}, 1 \mathrm{mM}$ EDTA, $10 \%$ (v/v) glycerol, $0.1 \%$ (v/v) Triton X-100, $5 \mathrm{mM}$ DTT, $1 \mathrm{mM}$ PMSF and $1 \%(\mathrm{w} / \mathrm{v})$ PVP, was added in a ratio of $1: 7(\mathrm{w} / \mathrm{v})$. The brei was filtered through four layers of cheesecloth and the homogenate was centrifuged at $1000 \mathrm{~g}$ for $5 \mathrm{~min}$ at $2^{\circ} \mathrm{C}$. The desalted extract was then centrifuged at $30000 \mathrm{~g}$ for $5 \mathrm{~min}$ at $2^{\circ} \mathrm{C}$. The supernatant was divided into $300 \mu \mathrm{L}$ aliquots, which were then frozen in liquid nitrogen and stored at $-80^{\circ} \mathrm{C}$ until analysis.

Ribulose-1,5-biphosphate carboxylase (RuBPC; EC 4.1.1.39) and glutamine synthetase (GS; EC 6.3.1.2) activity were determined as described in Astolfi et al. (2004).

\section{Determination of malondialdehyde content}

The level of lipid peroxidation was expressed as malondialdehyde (MDA) content and was determined as TBA reactive metabolites as described in Astolfi and Zuchi (2012). Briefly, fresh plant tissues (0.2 g) were homogenized in $10 \mathrm{ml}$ of $0.25 \%$ TBA made in 10\% TCA. Extract was heated at $95^{\circ} \mathrm{C}$ for $30 \mathrm{~min}$ and then quickly cooled on 
ice. After centrifugation at $10000 \times g$ for $10 \mathrm{~min}$, the $\mathrm{ab}$ sorbance of the supernatant was measured at $532 \mathrm{~nm}$. Correction of non-specific turbidity was made by subtracting the absorbance value taken at $600 \mathrm{~nm}$. The level of lipid peroxidation was expressed as $\mu \mathrm{mol} \mathrm{g}^{-1}$ fresh weight by using an extinction coefficient of $155 \mathrm{mM} \mathrm{cm}^{-1}$.

\section{Other measurements and statistics}

The concentration of chlorophyll content per unit area was estimated in attached leaves by a SPAD portable apparatus (Minolta Co., Osaka, Japan) using the first fully expanded leaf from the top of the plant.

Protein content was determined according to Bradford (1976) using BSA as standard.

\section{Shoot Fresh Weight (FW)}

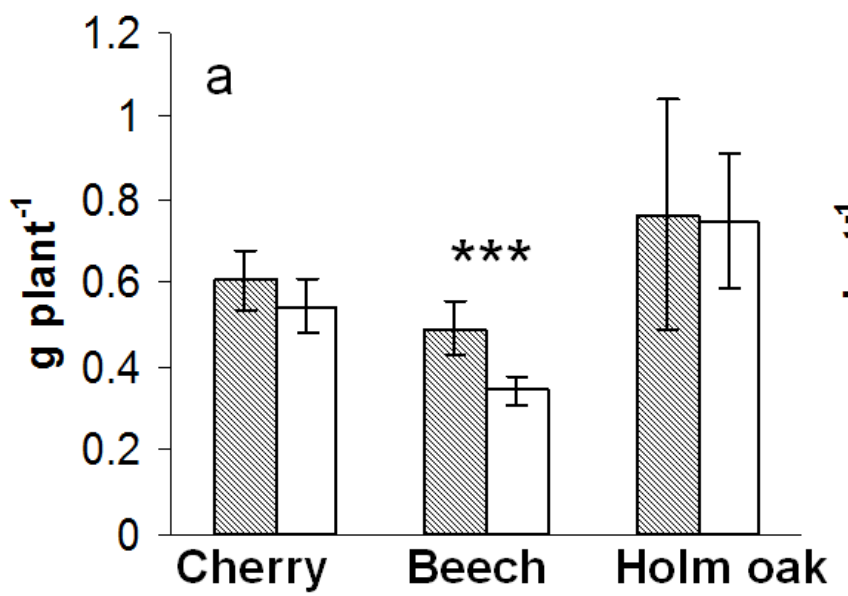

Each reported value represents the mean $\pm S D$ of data from four independent experiments on three measurements per experiment. Statistical analyses of data were carried out by ANOVA tests with the GraphPad InStat Program (version 3.06). Significant differences were established by posthoc comparisons (HSD test of Tukey) at $p<$ $0.0001, p<0.01$ or $p<0.05$.

\section{Results}

The growth and morphogenesis of the tested tree species were differently affected by different light conditions (Fig. 1 and 2). Fig. 1 shows the effect of fluorescent or LED lighting on shoot FW and DW of the different spe-

\section{Shoot Dry Weight (DW)}

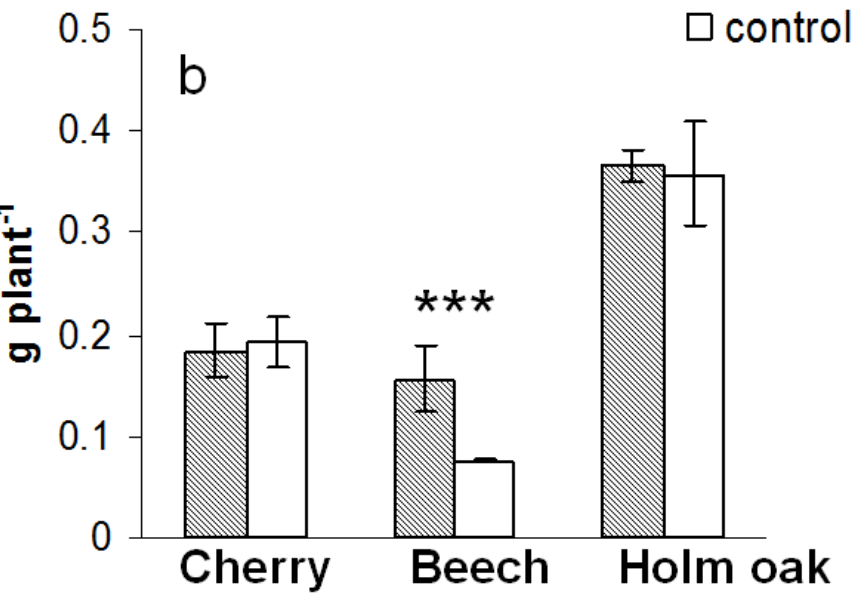

Fig. 1. Shoot fresh (a) and dry weight (b) of cherry, beech and holm oak plants grown for 30 days in growth chambers under fluorescent or LED light. Data are means \pm SD of four independent replications run in triplicate. Asterisks indicate significant differences between fluorescent and LED light grown plants $\left({ }^{*} p<0.05 ;{ }^{* *} p<0.01 ;{ }^{* * *} p<0.001 ;{ }^{* * * *} p<0.0001\right)$

\section{Shoot Height}

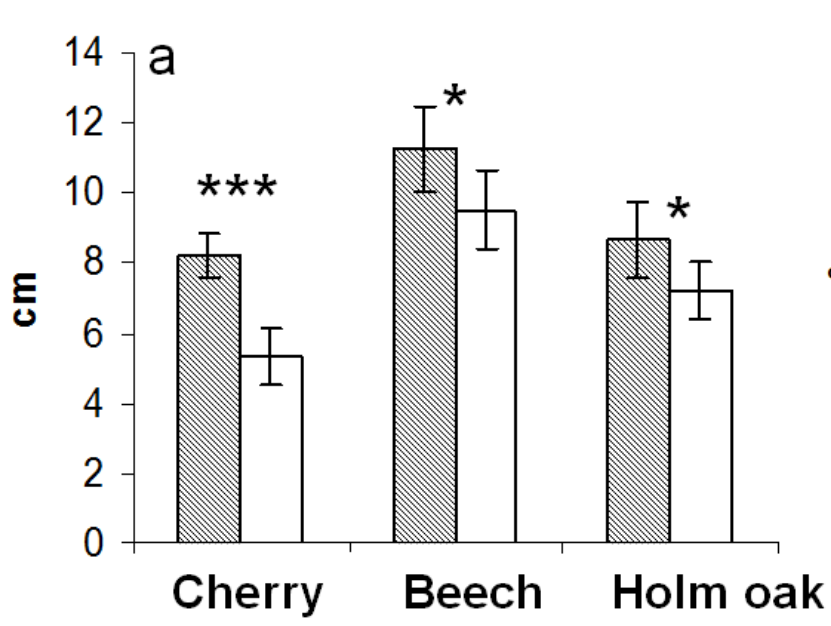

Leaf Area

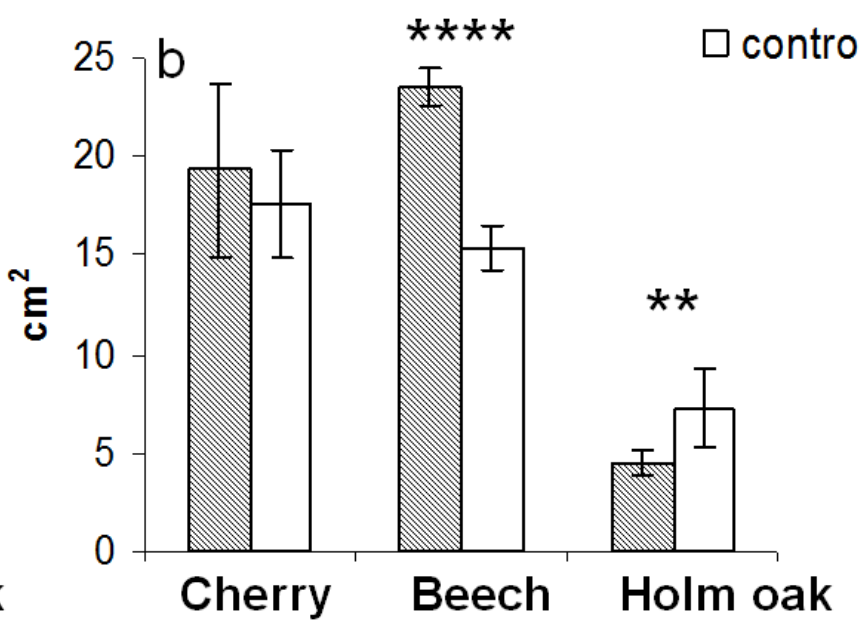

Fig. 2. Shoot height (a) and leaf area (b) of cherry, beech and holm oak plants grown for 30 days in growth chambers under fluorescent or LED light. Statistics as in Fig. 1 
SPAD Index

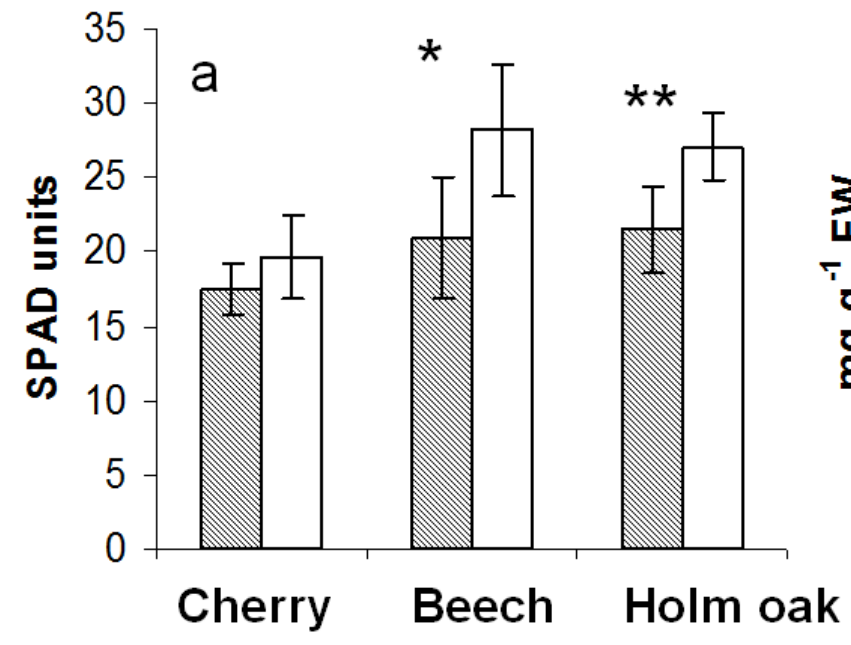

Carotenoids content $\mathbb{B}$ LED control

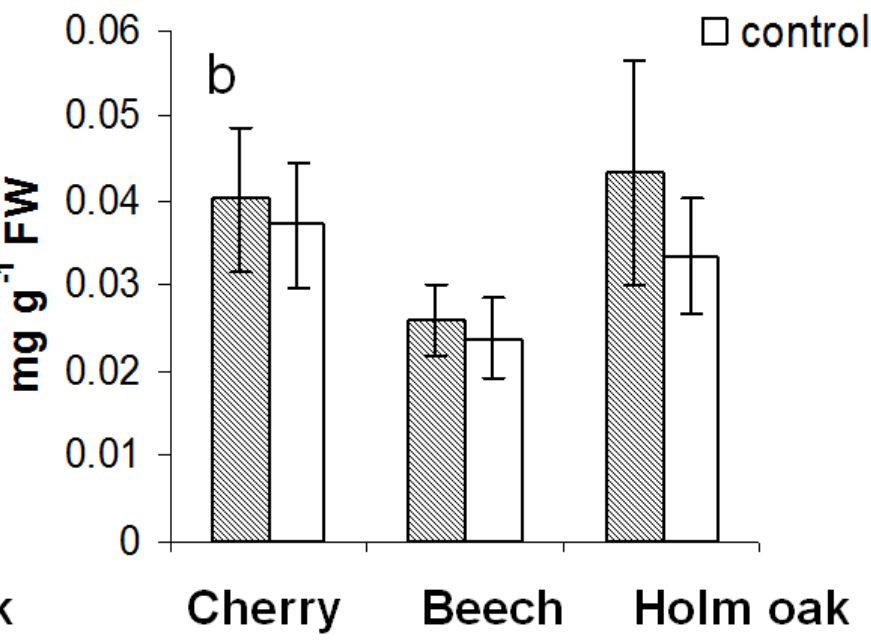

Fig. 3. Values of SPAD index (a) and carotenoids content (b) in leaves of cherry, beech and holm oak plants grown for 30 days in growth chambers under fluorescent or LED light. Statistics as in Fig. 1

cies. Both parameters were significantly higher in beech seedlings cultured under LEDs, whereas there was no significant difference in shoot $\mathrm{FW}$ or DW in both cherry and holm oak seedlings between different lighting. In particular, compared to fluorescent light-grown plants, beech grown under LEDs had $40 \%$ and $110 \%$ greater amounts of shoot fresh and dry matter respectively (Fig. 1).

Shoot height and leaf area were measured as parameters of shoot morphogenesis (Fig. 2). Shoots were significantly longer in plants cultured under LEDs in all species $(+20 \%$ for both beech and holm oak seedlings and $+55 \%$ for cherry) (Fig. 2a). The greatest leaf area was observed in beech seedlings under the LEDs (53\% higher than fluorescent grown control) and only in holm oak plants

\section{Protein Content}

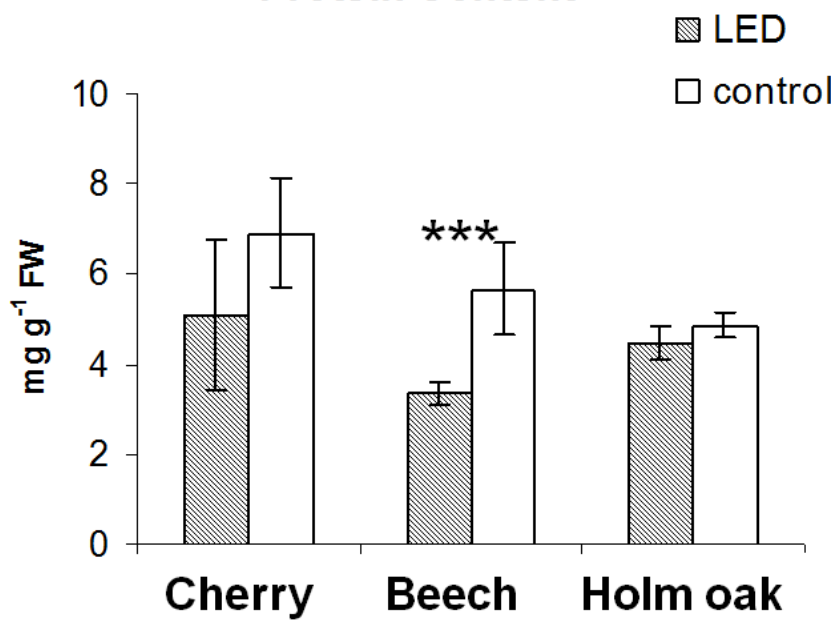

Fig. 4. Protein concentrations in shoots of cherry, beech and holm oak plants grown for 30 days in growth chambers under fluorescent or LED light. Statistics as in Fig. 1
LED lighting resulted in a significant decrease in leaf area (-40\%) (Fig. 2b).

The chlorophyll content was determined by a portable chlorophyll meter, model SPAD-502 (Soil and Plant Analysis Development) of Minolta Co. Ltd., Osaka, Japan (1989) that provide a sensitive and accurate index of leaf chlorophyll levels (Argenta et al., 2001) and relative data are shown in Fig. 3a. Young developing leaves from 30-day-old seedlings grown under LEDs exhibited lower chlorophyll levels with $10-20 \%$ decrease in SPAD units, depending on plant species. On the other hand, LED lights did not show any effect on leaf $\beta$-carotene content for any of the considered species (Fig. 3b).

Fig. 4 illustrates data from analysis of concentrations of protein in leaf tissues. Neither cherry nor holm oak showed statistically significant differences between different light conditions. In contrast, there was a lower accumulation of protein in beech shoots exposed to LED lights (-40\% compared with fluorescent plants) (Fig. 4).

Other factors that might be affected by changes in the light quality is the plant capability for carbon dioxide and ammonia assimilation, thus we investigated changes in the activities of key enzymes involved in carbon and nitrogen metabolism, namely RuBPC and GS (Fig. 5).

The carboxylase activities of RuBPC in the three species under different light conditions are showed in Fig. 5a. Compared to the fluorescent control, the activity of RuBPC decreased by $40 \%$ in leaves of cherry seedlings grown under LED lights, whereas a significant increase, $46 \%$ and $52 \%$, of this enzyme activity was observed in beech and holm oak, respectively, when exposed to LEDs.

The activities of GS in the three species under LEDs or fluorescent lamps are provided in Fig. 5b. There was no significant variation of GS activity in both cherry and holm 
RUBPC activity

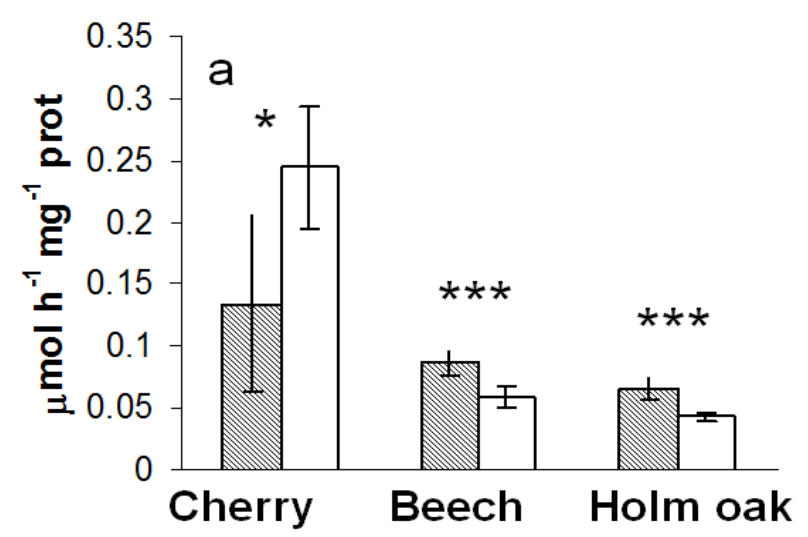

GS activity

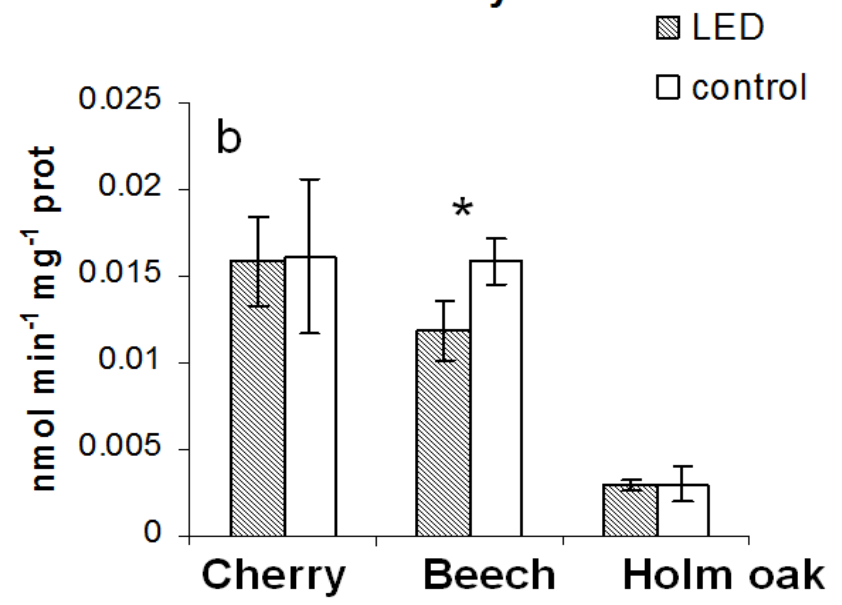

Fig. 5. Changes in RuBPC ( $\left.\mu \mathrm{mol} \mathrm{h}^{-1} \mathrm{mg}^{-1} \mathrm{prot}\right)$ (a) and GS (nmol min ${ }^{-1} \mathrm{mg}^{-1} \mathrm{prot}$ ) (b) activity in shoots of cherry, beech and holm oak plants grown for 30 days in growth chambers under fluorescent or LED light. Statistics as in Fig. 1

oak seedlings between different light conditions. In contrast, GS activity was about $25 \%$ lower in leaves of beech plants grown under LEDs than in the fluorescent control ones.

Oxidative stress due to the different light sources during pre-cultivation could be demonstrated by enhanced MDA content. As shown in Fig. 6, fluorescent lamps significantly increased MDA levels (30-70\% increase depending on plant species) in the leaves of seedlings (Fig. 6).

\section{Lipid Peroxidation}

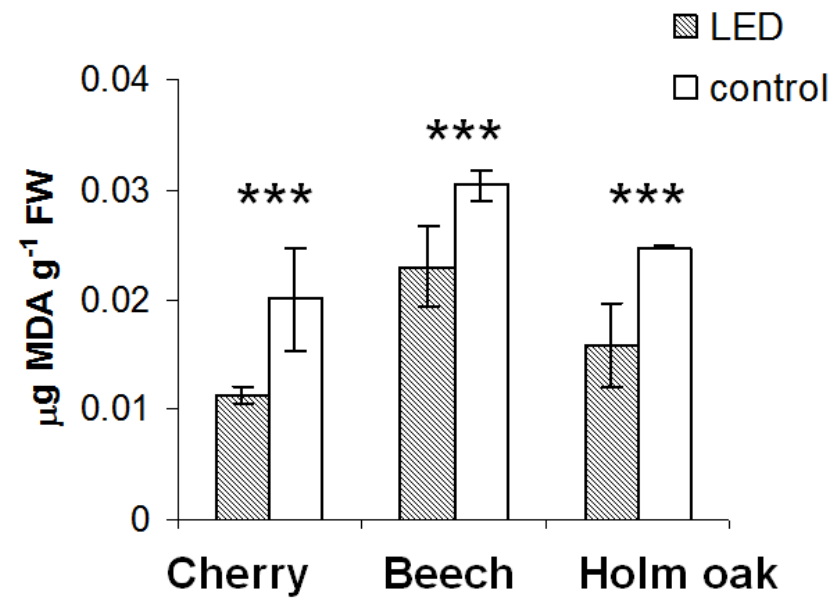

Fig. 6. MDA levels in shoots of cherry, beech and holm oak plants grown for 30 days in growth chambers under fluorescent or LED light. Statistics as in Fig. 1

\section{Discussion}

Growth chambers are generally provided with fluorescent lamps as light source showing a light emission in the visible (400-700 $\mathrm{nm})$ and invisible spectra $(700-850 \mathrm{~nm})$ with a yellow peak ( $589 \mathrm{~nm})$. However, these sources contain unnecessary wavelengths that are of low quality for promoting growth and show several limitations such as the fixed emission spectra. Recently, light emitting diodes (LEDs) have been developed as alternative light sources for plants because of their wavelength specificity and narrow bandwidth, small mass, volume, solid state construction, long life and minimum heating.

The objective of the present work was to evaluate the use of LEDs alternatively to fluorescent lamps for precultivation of seedlings of three Mediterranean woody species widely used in protective and productive planted forests. We have chosen new Valoya AP67 LEDs lamps because the red, far-red, blue and green LEDs are mixed so that they can generate a continuous spectrum unlike that of the narrow light bands produced by single LEDs.

Plants grew normally and without symptoms of disorder in mini-plug containers indicating that the cultural conditions adopted were appropriate. In particular, the new pre-cultivation method of mini-plug forest regeneration material has confirmed its efficacy with respect to the standard nursery practices (Kostopoulou et al., 2010; Mattsson et al., 2010).

Our results showed that plant response to light quality seems to be related to the plant species.

The better growth response to LED lighting was recorded in beech seedlings as measured by increase in fresh and dry weight, shoot height and leaf area (Fig. 1 and 2). Similar results were obtained in lettuce (Kim et al., 2004) and grapes (Poudel et al., 2008). On the other hand, for cherry and holm oak there was no significant difference in both fresh and dry biomass accumulation between LED and fluorescent grown plants (Fig. 1 a,b). However, LED lights significantly also increased cherry and holm oak shoot height (55\% and 20\% longer, respectively, compared to fluorescent plants) (Fig. 2a). It could be supposed that the increased shoot height of the three studied species may 
36

be related to the presence of green light in the spectrum which has been proven to be effective in stimulating early stem elongation (Folta et al., 2005).

Interestingly, in LED grown plants we observed a general reduction in chlorophyll content (measured as SPAD units), but carotenoid contents were not affected by the lighting condition (Fig. 3a). This finding is consistent with that reported in literature. For instance, Tanaka et al. (1998) reported that the contents of chlorophyll are reduced when plants are grown under red light. However, it is interesting to note that plant photosynthetic performance might be independent of the relatively low amount of chlorophyll as demonstrated by Saebo et al. (1995).

Consistently with this suggestion, we found that LEDinduced reduction of chlorophyll contents in beech and holm oak leaves resulted in an increased carboxylase capacity of RuBPC in the same plant species (Fig. 5a) suggesting an improvement of light-use-efficiency in these plants.

Carbon metabolism is highly interrelated with $\mathrm{N}$ assimilation pathway (Krapp and Truong, 2005): an increased production of photosynthate in response to changed availability of energy could provide extra $\mathrm{C}$ skeletons for amino acid synthesis and thus could determine an increased ammonia assimilation activity. Therefore the GS activity was investigated in different seedlings exposed to LED or fluorescent lights. Light modulation of GS activity is a well known phenomenon, since $80 \%$ of this enzyme is located in the chloroplast (McNally et al., 1983). The activity of this enzyme is therefore guaranteed by a sufficient supply of energy (ferredoxin, ATP) from photosynthesis. The pattern of GS activity suggests that this enzyme seems to be less affected by light source in all studied species except in beech seedlings (Fig. 5b), in which the reduction of GS activity is correlated to the reduction in protein content caused by LED exposure (Fig. 4). However, it cannot be ruled out that higher protein levels measured in fluorescent plants could be a result of the induction of protein synthesis so as to cope with oxidative stress.

Indeed, we found that growth of seedlings under fluorescent lamps significantly increased MDA contents in shoots. Enhanced accumulation of MDA is generally considered an oxidative stress marker in stressed plants (Bacelar et al., 2006; Liu et al., 2009). Free MDA is the final product of lipid peroxidation and its formation is routinely used as a general indicator of the extent of lipid peroxidation resulting from oxidative stress (Masia, 2003). Therefore, our results could indicate that pre-cultivation under fluorescent lamps increased the oxidative damage on cell membranes by lipid peroxidation.

The reported effect of light intensity on MDA contents in plants varies in literature, including increases in MDA contents at low light intensity (Huang et al., 2002; Sielewiesiuk, 2002; Zhang et al., 2011), and increases in MDA contents in high light conditions (Dias et al., 2011; $\mathrm{Xu}$ et al., 2010). Furthermore, in a recent study investigating both light quality and quantity by means of LED lights, Ilieva et al. (2010) reported that accumulation of high levels of MDA were observed in high light grown plants.

\section{Conclusions}

This is the first report which compares the effects of LED or fluorescent lights on MDA content in leaves of tree species, providing an indication of the extent of stress induced by different light conditions. On the basis of this evidence, we could only suggest that fluorescent light affected oxidative processes, which induced ROS and caused lipid peroxidation in all studied species. However, it is difficult to elucidate the significance of this response without further investigations.

Thus, since our study showed that using LEDs as light sources during the pre-cultivation phase of tree species resulted in improved plant growth and metabolic activity, we can conclude that the LED system here described may be used as an efficient alternative light source to obtain high quality forest material.

\section{Acknowledgements}

We thank Giulia and Luigi Sandoletti for their technical help. Financial support was provided by EU Project Regen-Forest.

\section{References}

Argenta G, Silva PRF, Bortolini CG, Forsthofer EL, Strieder ML (2001). Relationship of reading with the chlorophyll content of chlorophyll and extractable nitrogen in maize leaf. Rev Bras Fisiol Veg 13:158-167.

Ariz I, Esteban R, García-Plazaola JI, Becerril JM, Aparicio-Tejo PM, Moran JF (2010). High irradiance induces photoprotective mechanisms and a positive effect on $\mathrm{NH}_{4}^{+}$stress in Pisum sativum L. J Plant Physiol 167:1038-1045.

Astolfi S, Zuchi S (2012). Adequate S supply protects barley plants from adverse effects of salinity stress by increasing thiol contents. Acta Physiol Plant (in press) DOI: 10 1007/ s11738-012-1060-5.

Astolfi S, Zuchi S, Passera C (2004). Effects of cadmium on the metabolic activity of Avena sativa plants grown in soil or hydroponic culture. Biol Plant 48 (3):413-418.

Bacelar EA,Santos DL,Moutinho-Pereira JM,Gonçalves BC, Ferreira HF, Correia CM (2006). Immediate responses and adaptative strategies of three olive cultivars under contrasting water availability regimes: Changes on structure and chemical composition of foliage and oxidative damage. Plant Sci 170:596-605.

Bradford MM (1976). A rapid and sensitive method for the quantitation of microgram quantities of protein utilising the principle of protein-dye binding. Anal Biochem 72:248254.

Bubenheim DL, Bugbee B, Salisbury FB (1988). Radiation in 
controlled environments: Influence of lamp type and filter material. J Amer Soc Hort Sci 113:468-474.

Chazdon RL (2008). Beyond Deforestation: Restoring Forests and Ecosystem Services on Degraded Lands. Science 320:1458-1460.

Chen M, Chory J, Fankhauser C (2004). Light signal transduction in higher plants. Annu Rev Genet 38:87-117.

Ciccarese L, Anders M, Pettenella D (2012). Ecosystem services from forest restoration: thinking ahead. New Forests 43:543-560.

Cole RJ, Holla KD, Keene CL, Zahawi RA (2011). Direct seeding of late-successional trees to restore tropical montane forest. Forest Ecol Manag 261:1590-1597.

Dias MC, Pinto G, Santos C (2011). Acclimatization of micropropagated plantlets induces an antioxidative burst: a case study with Ulmus minor Mill. Photosynthetica 49(2):259266.

Folta KM, Koss LL, McMorrow R, Kim HH, Kenitz JD, Raymond W, Sager JC (2005). Design and fabrication of adjustable reed-green-blue LED light arrays for plant research. BMC Plant Biology 5:17.

Grossnickle SC (2005). Importance of root growth in overcoming planting stress. New Forests 30:273-294.

Huang WD, Wu LK, Zhan JC (2002). Effect of weak light on the peroxidation of membrane-lipid of cherry leaves. Acta Bot Sin 44:920-924.

Ilieva I, Ivanova T, Naydenov Y, Dandolov I, Stefanov D (2010). Plant experiments with light-emitting diode module in Svet space greenhouse. Adv Space Res 46:840-845.

Kim HH, Goins GD, Wheeler RM, Sager JC (2004). Greenlight supplementation for enhanced lettuce growth under red- and blue light emitting diodes. HortSci 39(7):16171622.

Kostopoulou P, Radoglou K, Dini-Papanastasi O, Spyroglou G (2010). Enhancing planting stock quality of Italian cypress (Cupressus sempervirens L.) by pre-cultivation in mini-plugs. Ecol Engin 36:912-919.

Krapp A, Truong HN (2005). Regulation of C/N interaction in model plant species. J Crop Improv 15:127-173.

Li H, Tang C, Xu Z, Liu X, Han X (2012). Effects of Different Light Sources on the Growth of Non-heading Chinese Cabbage (Brassica campestris L.). J Agr Sci 4:262-273.

Liu XY, Guo SR, Xu ZG, Jiao XL, Takafumi T (2011). Regulation of chloroplast ultrastructure cross-section anatomy of leaves and morphology of stomata of cherry tomato by different light irradiations of light-emitting diodes. HortSci 46:1-5.

Liu ZJ, Zhang XL, Bai JG, Suo BX, Xu PL, Wang L (2009). Exogenous paraquat changes antioxidant enzyme activities and lipid peroxidation in drought stressed cucumber leaves. Sci Hortic 121:138-143.

Masia A (2003). Physiological effects of oxidative stress in relation to ethylene in postharvest produce, p. 165-197. In:
37

Hodges DM (Eds.). Postharvest Oxidative Stress in Horticultural Crops. Food Products Press, New York.

Massa GD, Kim HH, Wheeler RM, Mitchell CA (2008). Plant productivity in response to LED lighting. HortSci 43:19511956.

Mattsson A, Radoglou K, Kostopoulou P, Bellarosa R, Simeone MC, Schirone B (2010). Use of innovative technology for the production of high-quality forest regeneration materials. Scand J For Res 1:1-7.

McNally SF, Hirel B, Gadal P, Mann AF, Stewart GR (1983). Glutamine synthetases of higher plants. Plant Physiol 72:2225

Navarro RM, Retamosa MJ, Lopez J, Del Campo A, Ceaceros C, Salmoral L (2006). Nursery practices and field performance for the endangered Mediterranean species Abies pinsapo Boiss. Eco Eng 27:93-99.

Nhut DT, Takamura T, Watanabe H, Murakami A, Murakami K, Tanaka M (2002). Sugar-free micropropagation of Eucalyptus citriodora using light-emitting diode (LEDs) and film-rockwool culture system. Environ Control Biol 40:147155.

Niinemets Ü (2010). Responses of forest trees to single and multiple environmental stresses from seedlings to mature plants: past stress history stress interactions tolerance and acclimation. Forest Ecol Manage 260:1623-1639.

Poudel RP, Kataoka I, Mochioda R (2008). Effect of red- and blue light-emitting diodes on growth and morphogenesis of grapes. Plant Cell Tiss Organ Cult 92:147-153.

Saebo A, Krekling T, Appelgren M (1995). Light quality affects photosynthesis and leaf anatomy of birch plantlets in vitro. Plant Cell Tiss Org 41:177-185.

Schuerger AC, Brown CS (1994). Spectral quality may be used to alter plant disease development in CELSS. Adv Space Res 14:395-398.

Sielewiesiuk J (2002). Why there are photodamages to photosystem II at low light intensities. Acta Physiol Plant 24:399406.

Smith FW, Cybinski D, Rae AL (1999). Regulation of expression of genes encoding phosphate transporters in barley roots, 145-150 p. In: Gissel-Nielsen G, Jensen A (Eds.). Plant Nutrition - Molecular Biology and Genetics. Kluwer Academic Publishers, Dordrecht.

Stutte GW, Edney S, Skerritt T (2009). Photoregulation of bioprotectant content of red leaf lettuce with light-emitting diodes. HortSci 44:79-82.

Tanaka M, Takamura T, Watanabe H, Endo M, Yanagi T, Okamoto K (1998). In vitro growth of Cymbidium plantlets cultured under superbright red and blue lightemitting diodes (LEDs). J Hortic Sci Biotech 73:39-44.

Tennessen DJ, Singsaas EL, Sharkey TD (1994). Light-emitting diodes as a source for photosynthesis research. Photosynth Res 39:85-92.

Wang FX, Wang ZY, Leeb JHW (2007). Acceleration of veg- 
38 etation succession on eroded land by reforestation in a subtropical zone. Ecol Engine 31:232-241.

Wang H, Jin JY (2005). Photosynthetic rate chlorophyll fluorescence parameters and lipid peroxidation of maize leaves as affected by zinc deficiency. Photosynthetica 43:591-596.

Wang Y, Woodcock CE, Buermann W, Stenberg P, Voipio P, Smolander H, Hame T, Tian Y, Hu J, Knyazikhin Y, Myneni RB (2004). Evaluation of the MODIS LAI algorithm at a coniferous forest site in Finland. Remote Sens Environ 91:114-127.

Wilson BC, Jacobs DF (2006). Quality assessment of temperate zone deciduous hardwood seedlings. New Forests 31:417433.

Xu Y, Sun X, Jin J, Zhou H (2010). Protective effect of nitric oxide on lightinduced oxidative damage in leaves of tall fescue. J Plant Physiol 167:512-518.

Yamori W, Evans JR, Von Caemmerer S (2010). Effects of growth and measurement light intensities on temperature dependence of $\mathrm{CO}_{2}$ assimilation rate in tobacco leaves. Plant Cell Environ 33:332-343.
Yeh N, Chung JP (2009). High-brightness LEDs-Energy efficient lighting sources and their potential in indoor plant cultivation. Renew Sust Energ Rev 13:2175-2180.

Zhang XL, Jia XF, Yu B, Gao Y, Bai JG (2011). Exogenous hydrogen peroxide influences antioxidant enzyme activity and lipid peroxidation in cucumber leaves at low light. Sci Hortic 129:656-662.

Zuchi S, Astolfi S (2012). Changes in growth irradiance are reflected on $\mathrm{H}^{+}$ATPase activity of plasma membrane enriched vesicles from maize (Zea mays L.) root. J Plant Physiol 169:50-54.

Zuchi S, Cesco S, Astolfi S (2012). High S supply improves Fe accumulation in durum wheat plants grown under Fe limitation. Environ Exp Bot 77:25-32. 